\title{
Personality Traits and Leadership Styles and Management of the School Principals and Assistant Principals of MSU Community High Schools: Basis for Training and Development
}

\author{
${ }^{1}$ Myrna M. Asira, ${ }^{2}$ Rohanie Musa-Lucman, ${ }^{3}$ Farida B. Muti, ${ }^{4}$ Anabelie V. Valdez \\ Mindanao State University, External High School
}

\begin{abstract}
This study surveyed the personality traits and leadership and management styles of the school principals and assistant principals in the 13 MSU Community High Schools. Descriptive correlational research design was used to determine the extent relationship of the personality traits and leadership styles practice by the principal and assistant principal using survey questionnaires. Findings revealed that the principal and assistant principal possess different personality traits but the most common traits were task oriented, fast paced and task oriented, slow paced. Leadership styles practice by the principal and assistant principal also varies but the democratic leadership styles were mostly used and directing and coaching is their common managerial approach. Moreover, findings showed that the personality traits of the school principals and assistant principals have positive correlation to their leadership styles and the relationships are highly significant. On the basis of the findings, the study concluded that personality traits of a person have positive and significant influence to their leadership styles.This implies that leadership styles of a person are shape according to their personality traits.
\end{abstract}

Keywords: Personality Traits, Leadership Styles, Management Approach, School Principal, Assistant School Principal

\section{Introduction}

School principals and assistant principals plays vital role in a school organization. They are responsible in managing the faculty and staff to meet the need of the school and to pursue collective goals for the continuous development of the quality of education that the school could offer. However, the culture of organization varies from organization to organization depending on the leadership style of the heads of the organization, as well as the behaviour of the leaders and members of the organization.

Meranaw in nature has unique personality in dealing people particularly in terms of management and leaderships. The personality of a leader might be influenced or defend on their personality traits. Research findings of Valdez and Villa (2018) mentioned that the leadership styles significantly influence by the personality traits of the leader which in turn influence also to organizational climate and job satisfaction of the employees.

The success of an organization depends on the unique culture and distinct atmosphere of an organization that is felt by its member and clients. It is also hold true to any kind of organization like in the school or academic institutions where the leaders are responsible in shaping its members towards their common goal. According to McLaughin (2017) leaders should have ability to shape its members, but they can shape in accordance to their leadership styles.

Leadership styles are important aspect in any type of organization. A good leader must have more than one leadership styles. Management styles are not something to be try to see it hysterics, but rather, should be modified to the exacting demands of the circumstances, the exacting needs of the people involved and the particular challenges facing the organization (Jones, 2016).Many researchers believed the idea that leadership and its associated skills could be taught and learned and great leaders were not just born but could be made (VidulaBal Michael Campbell Judith Steed Kyle Meddings, 2008). 
The knowledge and power of an organizational leader is very crucial in any organization to ensure that every employee, from top to bottom is having a friendly organizational climate. The vision, mission, goals and objectives of an organization must be clear to all members of the organization. Transparency and regular reporting is very important in the organizational management in order to motivate the members' performances, and successes. A good organizational leader must apply two-way communication among its members from top to bottom and takes responsibilities and duties that are reasonable and legally bounded. Azusa Pacific University (2016) emphasized that a highly effective leaders are not afraid to be decisive and to make tough calls quickly when circumstances required it. Great leaders must stick to its decision unless compelling reasons supports for it change.

Organizational leaders must successfully equip with knowledge and skills to lead the organizations through clarity of purpose and effective collaboration in the organization, building and motivating the employee or teams in designing and delivering efficient and effective services with utmost friendly environment. Organizational leaders must provide opportunity to build the self-esteem of its members, motivate them, empower and continuously provide professional growth for effective strategies and innovative approaches in delivering optimum services to the clienteles. TDK Technologies IT (2016) listed cornerstones of good leadership namely: 1) truth telling; 2) promise keeping; 3) fairness; and 4) respect for individual.Current theology promotes the idea of using more than one leadership style in the workplace to develop and draw out the best efforts of all members in the organization (Martin, 2015).

We all know that leaders do not possess the same attitude, perspective and philosophy resulting to have different leadership style and personality traits. Leadership styles also vary with the kind of people they interact and deal with. Thus, this paper conduct surveys on the different leadership styles and personality traits of the school principals and assistant school principals to determine the best leadership style to establish its relationship and effects to the academic performance of the school.

\section{Research Objectives}

This study aimed to identify the different leadership styles and personality traits of the school principals and assistant school principals of the 13 MSU Community High Schools. Specificallysought answer to the following research questions:

1. What are the most common personality traits of the school principals and assistant school principals of the 13 MSU Community High Schools?

2. What are the leadership styles of the school principals and assistant school principals of the 13 MSU Community High Schools?

3. How do the school principals and assistant school principals manage their respective school?

4. How do the school principals and assistant school principals perceived their leadership styles?

5. What is the relationship of personality traits and leadership styles?

6. What is the proposed training and development for leadership style improvement?

\section{Research Design}

\section{Methods}

This study used descriptive-correlational research design. Description was used in describing and presenting the perceptions of the respondents while correlation was used to determine the relationship of leadership styles and personality traits employed by the respondents.

\section{Respondents of the study}

The respondents of this study were the school principals and assistant school principals of the thirteen (13) MSU Community High Schools. They answered the questionnaire on their most convenient time. 


\section{Research Instruments}

Survey questionnaires are the main instruments used in the gathering of date. There were three sets of questionnaire used namely: a) management and leadership styles, b) questionnaire on respondent's perception on their leadership styles, and c) questionnaire on the personality traits of the respondents. The questionnaires were adapted from the 7 secrets to successful management, 5-minute personality tests which are all modified and validated in the Philippine setting.

\section{Data Gathering Procedure}

Data gathering started after securing the entry protocol, consent and validation of the adapted questionnaires. Since MSU Community High Schools are strategically located around the Lake Lanao with few located far apart, data gathering was done during principals meeting and seminar workshops. For convenience, the respondents were allowed to answer the questionnaire at their most convenient time with voluntarism. Secondary information was also gathered from feedbacks of the faculties and personal observations.

\section{Data Analysis}

The completed questionnaires were checked, tallied and analyse statistically using Statistical Package for Social Sciences (SPSS). In the presentation and discussions of results both quantitative and qualitative were employed.

\section{Respondents Personality Traits}

\section{Findings and Discussions}

Table 1

Personality traits of the school principals and assistant school principals of the 13 MSU Community High Schools

\begin{tabular}{|l|l|r|}
\hline \multicolumn{1}{|c|}{ Personality Traits } & F & Mean \\
\hline Task Oriented, Fast Paced & 8 & 27.586 \\
\hline People Oriented, Fast Paced & 4 & 13.793 \\
\hline People Oriented, Slow Paced & 4 & 13.793 \\
\hline Task Oriented, Slow Paced & 7 & 24.138 \\
\hline People \& Task Oriented With Fast And Slow Paced & 5 & 17.241 \\
\hline Task Oriented With Fast And Slow Paced & 1 & 3.448 \\
\hline
\end{tabular}

Table 1 depict the different personality traits of the school principals and assistant school principals of the 13 MSU community high schools. As shown, many of them were task oriented and fast paced with a mean of 27.586. This kind of personality is motivated with results challenges, credit for achievements that lead them to exert more action and power. In decision making, they impulsive and results focused. They usually make quick decision involving very few facts.

Next kind of personality trait possesses by the principal and assistant principal is task oriented but slow in paced. This kind of person work slowly to make sure they are accurate and motivated by desire to be right and quality. In decision making, they needs lots of information before they will make a decision.

Another personality of the principal and assistant principal is people oriented either fast or slow paced. Their desire for good relationships and appreciation of others and recognition and approval of others motivated them to work. They are more concern on their popularity than achieving tangible results and in making decision the fast paced are intuitive and fast but usually makes a lot of right and wrong ones while the slow paced makes decisions more slowly, and usually gathered input from others. 
The least personality traits of the school principal and their assistants is task oriented with either fast of slow paced. The management of the fast paced is more on quick results. They hate wasting time and like to get right to the point. While, the slow paced tend to work slowly to make sure they are accurate. They need security, and gradual change.

These results showed that the personality traits of the principal and their assistants vary. It is very important to note that according to the study of Garcia, M., Duncan, P.Carmody-Bubb, M., and Ree, M.J. (2013) personality traits and leadership style are interrelated.

\section{Respondents Leadership Styles}

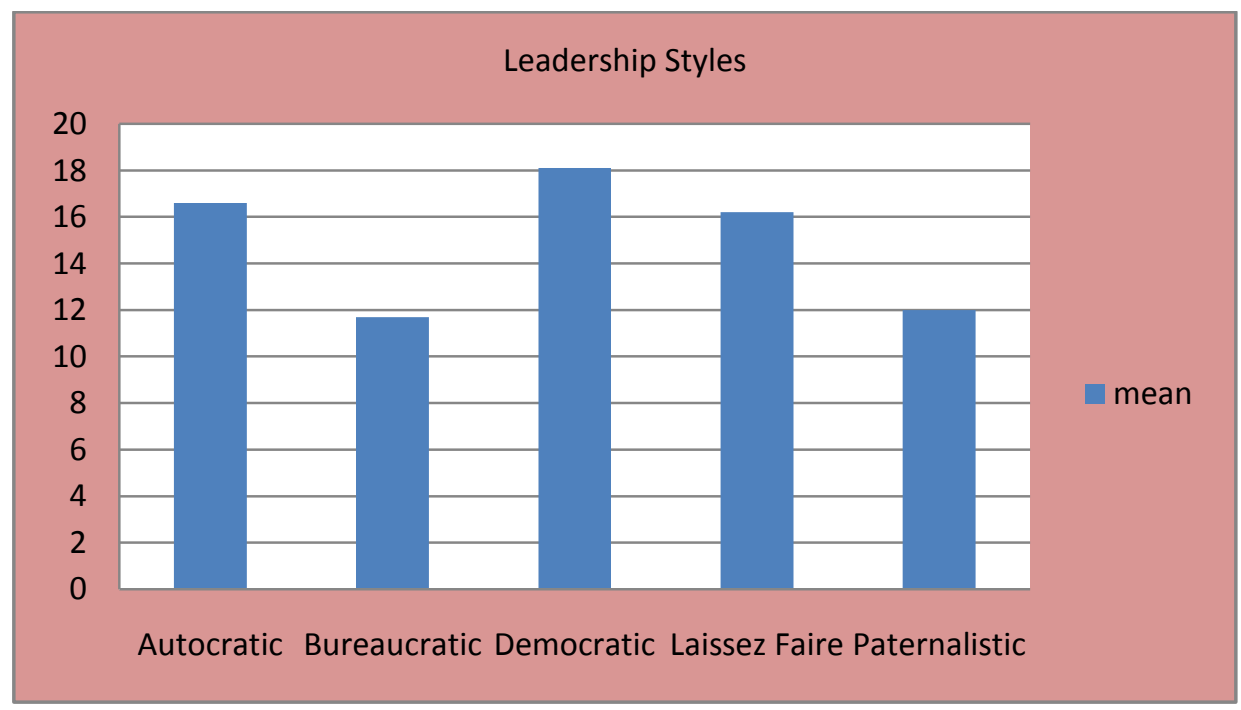

Figure 1

Leadership styles of the school principals and assistant school principals of the 13 MSU Community High Schools

Figure 1 shows the different leadership styles of the school principals and their assistants. It is clearly shown in the figure that the most prominent leadership styles they practice is a democratic leadership style, next in line is being autocratic and then laissez faire, paternalistic and bureaucratic as the least practice.

Since many of the principal and assistant principal practice democratic leadership style, obviously they entertain the voices and opinions of their teachers/subordinate particularly in decision making. This kind of leadership has open-door policy allowing the teachers to communicate freely. However, the principals and assistant principals' respondents who practice autocratic leadership, they act as the sole person in authority. Their teachers/employees are just a replaceable resource and not the core member of the school. They did not entertain any aspect in the employees' satisfaction.

On the other hand, laissez faire, paternalistic and bureaucratic leadership style practice by the principals and assistant principals is a manifestation that they allow their teachers to about the meetings what they want and with very liberal management which in turn make the teachers work taking for granted, act like parent than a boss and consider their teachers as the heart of their school organization, dependent on what is written in the book and follow the rules rigorously and ensure that their staff will do the same respectively. Apak and Gümüs (2015) mentioned in their findings that a leader who appliesfair and just disciplinary actions to the employees in the school will lead them to be more motivated at their work. 


\section{Respondents Management Approaches}

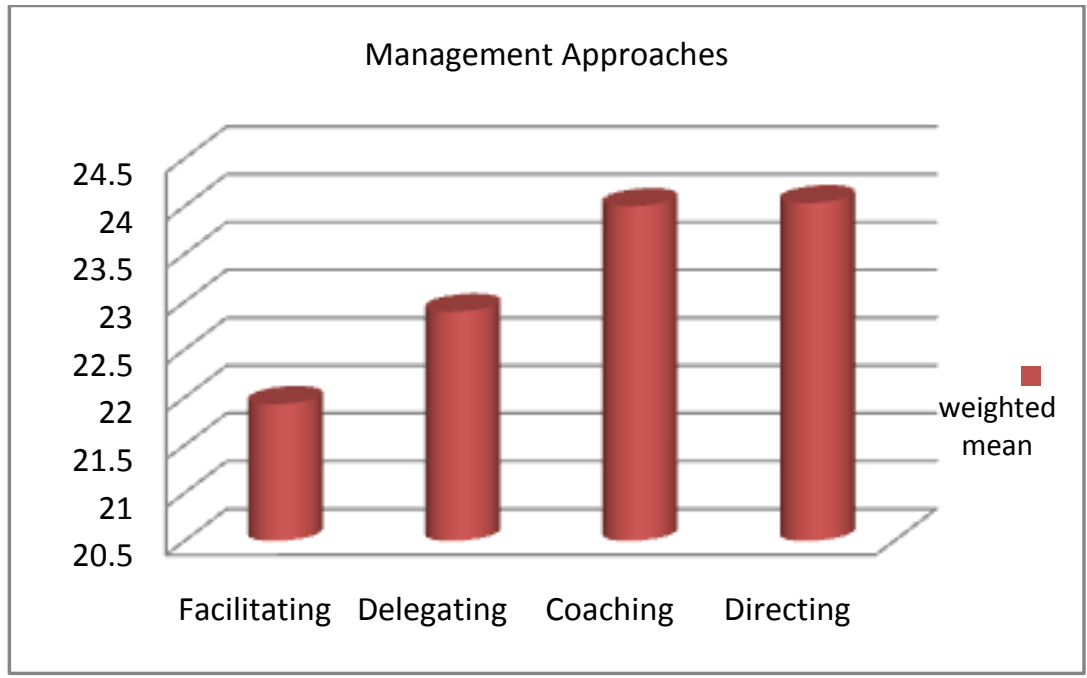

Figure 2

Management approaches used by school principals and assistant school principals of the 13 MSU Community High Schools

Figure 2 reveal the management approaches usually practice by the school principals and the assistant principals. As shown, the school principals and the assistant principals usually use directing and coaching approach in managing their teachers and other staff. This means that they provide detailed instructions, specific goals, check the teachers frequently and motivate, praise, convince and provide feedbacks to their teacher and staff respectively.

Another management approach practice by the principals and assistant principals is delegating and facilitating. In delegating approach, they designate responsibilities to their teachers and staff and let them find and correct their own errors. In facilitating, the principals and assistant principals will involve their teachers and staff in making decision, and planning. They make sure that their teachers and staffs feel free to ask questions and discuss important concerns in meetings. The attitudes and behaviour of the leader tend to increase the employees motivation and confidence at their work (Apak and Gümüs, 2015).

\section{Perceptions of the School Principals and Assistant Principals to their Leadership and Management Styles}

Table 2

Perceptions of School Principals and Assistant School Principals to their Leadership and Management

\begin{tabular}{|l|l|c|l|}
\hline & STATEMENTS & $\begin{array}{c}\text { Weighted } \\
\text { Mean }\end{array}$ & \multicolumn{1}{|c|}{ Description } \\
\hline 1 & $\begin{array}{l}\text { Employees/Students need to be supervised closely, or they are not likely to do their } \\
\text { work. }\end{array}$ & 3.931 & Agree \\
\hline 2 & Employees/students want to be a part of the decision-making process & 4.207 & Strongly agree \\
\hline 3 & $\begin{array}{l}\text { In complex situations, leaders/teacher should let subordinates work problems out on } \\
\text { their own. }\end{array}$ & 4.034 & Strongly agree \\
\hline 4 & It is fair to say that most employees/students in the general population are lazy & 2.552 & Neutral \\
\hline 5 & Providing guidance without pressure is the key to being a good leader/teacher & 4.276 & Strongly agree \\
\hline 6 & Leadership requires staying out of the way of subordinates as they do their work & 3.103 & Agree \\
\hline 7 & $\begin{array}{l}\text { As a rule, workers must be given rewards or penalty in order to motivate them to } \\
\text { achieve organizational objectives }\end{array}$ & 4.069 & Strongly agree \\
\hline 8 & Most workers desire frequent and helpful message from their leaders. & 4.241 & Strongly agree \\
\hline \hline
\end{tabular}


Volume: 2 Issue: 3

May to June 2019

www.ijsmsjournal.org

\begin{tabular}{|c|c|c|c|}
\hline 9 & As a rule, leaders should allow subordinate to assess their own work. & 4.138 & Strongly agree \\
\hline 10 & Most employees/students feel insecure about their work and need direction & 3.172 & Agree \\
\hline 11 & Leaders need to help subordinates accept responsibility for completing their work & 4.034 & Strongly agree \\
\hline 12 & Leaders should give subordinates complete freedom to solve problems on their own & 4.034 & Strongly agree \\
\hline 13 & The leader is the chief judge of the achievements of the members of the group & 4.241 & Strongly agree \\
\hline 14 & It is the leader's job to help subordinates find their "passion" & 3.724 & Agree \\
\hline 15 & In most situations, workers prefer little input from the leader & 3.483 & Agree \\
\hline 16 & Effective leaders give orders and clarify procedures & 4.552 & Strongly agree \\
\hline 17 & People are basically competent and if given a task will do a good job & 4.379 & Strongly agree \\
\hline 18 & In general, it is best to leave subordinates alone & 2.931 & Neutral \\
\hline 19 & Make my own decision & 3 & Agree \\
\hline 20 & Tell others what to do & 2.862 & Neutral \\
\hline 21 & Suggest a decision to others & 3.241 & Agree \\
\hline 22 & Persuade others to do things my way & 2.448 & Neutral \\
\hline 23 & Participate just like any other person & 2.897 & Neutral \\
\hline 24 & Provide resources to others & 2.759 & Neutral \\
\hline 25 & Gather others feedback before deciding & 3.241 & Agree \\
\hline 26 & Rely on my own judgement & 2.862 & Neutral \\
\hline 27 & Make sure the majority rules & 2.897 & Neutral \\
\hline 28 & Turn decision over others & 2.621 & Neutral \\
\hline 29 & Ask others to brainstorm choices & 2.414 & Neutral \\
\hline 30 & Share my own ideas & 2.103 & Neutral \\
\hline
\end{tabular}

Legend: Strongly Agree (SA) = 4-5 $\quad$ Agree $(A)=3-4.99 \quad$ Neutral $(\mathrm{N})=2-2.99 \quad$ Disagree $(\mathrm{D})=1-1.99$

Strongly Disagree (SD) $\quad=0-.99$

Table 2 displays the different perceptions of the principals and assistant principals on their leadership and management style. As shown, they strongly agree on statement number 2, 3, 5, 7, 8, 9, 11, 12, 13, 16 and 17. These statements are mostly favour on democratic leadership style with coaching and facilitating approach. In statement 1 , $6,10,14,15,19,21$ and 25, they tend to agree. These statements are in favour of autocratic leadership with more directing approach. This is congruent to the leadership style of the principals and assistant principals in figure 2 where autocratic leadership style is the next in rank that commonly practice. For the other statements, the principals and assistant principals preferred to be neutral.

\section{Relationship of Personality Traits and Leadership Styles}

Table 3

Relationship of Respondents Personality Traits and Leadership Styles

\begin{tabular}{|l|r|r|r|c|}
\hline \multicolumn{1}{|c|}{ Variable } & Mean & $\begin{array}{c}\text { Standard } \\
\text { Deviation }\end{array}$ & $\begin{array}{c}\text { Significant } \\
\text { Value }\end{array}$ \\
\hline Personality Traits & 3.00 & 1.604 & & \\
And Leadership Styles & 2.934 & 1.389 & $0.844^{* *}$ & .000 \\
\hline
\end{tabular}

Legend: ${ }^{* *}$ Correlation is significant at the 0.01 level (2-tailed).

Table 3 displays the relationship of personality traits possessed by the principal and assistant principals and their leadership styles. As revealed in the table, personality traits and leadership styles are significantly correlated $(\mathrm{r}=0.844 ; 0.000)$. Since the correlation of the two variables is positive with value of 0.844 which is almost or near to 
1 , it indicates that the personality traits of the principals and assistant principals is highly and positively correlated to their leadership styles. This implies that if they possess good personality traits, they also a good leader.

The findings of this study are supported by the findings of the different similar studies previously conducted from different countries. Research findings of Tatlah, I.A., Naz, F., Khalid, A., and Iqbal, M. Z. (nd) revealed that leader's personality characteristics and behaviors positively related and influence their leadership styles. Moreover, research findings of Tatlah (2015) about the influence of personality traits on leadership styles publicized that traits are linked with leadership styles, and a leader who are people and task oriented will have a more effective leadership.Kenya Peris M. Koech\&Prof. G.S Namusonge (2012) research findings about leadership styles pointed out that organizational performance is not correlated to laissez-faire leadership. Effective leadership should be transformational.

\section{Conclusion}

Based on the findings of the study, it is concluded that individual person is unique in the same way that the school principals and the assistant principals possess different personality traits, leadership and management. Leadership and management are shaped or influence with the personality traits that an individual acquired and possess.

\section{Recommendation}

From the findings and conclusions it is recommended that educational leaders such as the school principals and assistant principals should abandon laissez-faire leadership practice and tend to be more democratic, transformational and authoritative sometimes. Furthermore, they should endeavour more enhancement and development of positive attributes as a leader to become role models that inspires their teachers, staff and students. They may pay more attention towards achievement and growth for everyone. Lastly, trainings and development for the school administrators must be regularly conducted.

\section{List of Proposed Training}

1. Nurturing the management, leadership, and education supervision of the principals, assistant principals and guidance counselors.

2. Capacitating the management, leadership, and education supervision of the principals, assistant principals and guidance counselors using transformational leadership approach

\section{References}

[1] Apak and Gümüs (2015). A Research about the Effect of the Leadership Qualities of Public Administrators on the Motivation of the Employees. Science Direct, ELSEVIER.

[2] Garcia, M., Duncan, P.,Carmody-Bubb, M., and Ree, M.J. (2014). You Have What? Personality! Traits That Predict Leadership Styles for Elementary Principals. School of Business and Leadership, Our Lady of the Lake University, San Antonio, USA.Copyright (C) 2014 by authors and Scientific Research Publishing Inc.

[3] Kenya Peris M. Koech\&Prof. G.S Namusonge (2012). The Effect of Leadership Styles on Organizational Performance at State Corporations in

[4] Martin, M. (2015).Business News Daily Contributor July 21, 2015 02:16 pm EST CEB Valtera, Rolling Meadows, Illinois 60008,

[5] Schneider, B., Ehrhart, M.G., and Macey, W.H.(2013).Organizational Climate and Culture.Vol. 64:361-388 https://doi.org/10.1146/annurev-psych-113011-143809

[6] Tim Kuppler(2014). Changing the World—One Organization at a Time®.๑ 2014 The Culture Advantage. All Rights Reserve

[7] Tatlah, I. A. (2011). Influence of Personality Traits on Leadership Styles: A Secondary Level Study. University of Management \& Technology (UMT) www.ijbcnet.com International Journal of Business and Commerce Vol. 2, No.1: Sep 2012[01-12] (ISSN: 2225-2436) Published by Asian Society of Business and Commerce Research

[8] Tatlah, I.A., Naz, F., Khalid, A., and Iqbal, M. Z. (nd) Influence of Personality Traits on Leadership Styles: a secondary level study Electronic copy available at: http://ssrn.com/abstract=1826723 